\title{
Recovering from acquired childhood aphasia (ACA) - 20 years later, learning about the neuroplasticity of language
}

\author{
Martin Lauterbach ${ }^{\mathrm{a}, *}$, Ricardo Gil da Costa ${ }^{\mathrm{b}}$, Gabriela Leal ${ }^{\mathrm{c}}$, Klaus Willmes ${ }^{\mathrm{d}}$ and Isabel Pavão Martins ${ }^{\mathrm{a}}$ \\ ${ }^{\mathrm{a}}$ Language Laboratory, Institute of Molecular Medicine, University of Lisbon, Lisbon, Portugal \\ ${ }^{\mathrm{b}}$ Salk Institute, San Diego, CA, USA \\ c Santa Maria Hospital, Lisbon, Portugal \\ d Section Neuropsychology, University Hospital, RWTH Aachen University, Aachen, Germany
}

\section{Introduction}

Language is at the core of human cognitive abilities and the mechanisms associated with neural recovery from aphasia are still largely unknown. Important insights have been reported, such as: i) Significantly better recovery occurs, if the brain lesions leading to aphasia were suffered during childhood (ACA); ii) that perilesional map expansion and transference of language functions to homologue areas in the contralateral hemisphere are thought to be two main processes sustaining this neuroplasticity [1]. From the study of peri-natal brain lesions of left hemisphere is known that they are often associated with language transfer to the right hemisphere [2-4].

We investigated if potential factors underlying the neuroplasticity of language (such as the developmental linguistic stage at onset of aphasia and size of the lesion) would significantly contribute to determine the recovery strategy. We report the a follow-up study of three cases of left frontal subcortical isquemic strokes about 20 years after onset of aphasia.

\section{Method}

\subsection{Participants}

Three young adults ( 1 female DF, 2 male JAF + JPF) that suffered from a aphasia, due to a left frontal sub-

*Corresponding author. E-mail: mlauterbach@fm.ul.pt. cortical lesion (age at onset JAF 2,1; DF 2,7; JPF 13,5 years respectively), performed an extensive neurolinguistic testing (age at testing 31,$5 ; 33,4 ; 26,3$ years respectively) applying 20 different neurolinguistic tests.

The activation pattern of the 3 patients were compared to 4 ( 3 female, 1 male) healthy controls (mean age of 26,3 years and 15 years of formal education).

\section{2. $M R I$}

MRI data acquisition was performed on 3T Philips Achieva Scanner. Two fMRI language paradigms, semantic decision paradigm with both visual and auditory presentation were applied. Visual semantic decision paradigm, written in block design; image acquisition was performed in a continuous manner (TR $2000 \mathrm{~ms}, 160$ volumes). Auditory semantic decision paradigm, written in event design; image acquisition was performed in sparse design, in order to present the auditory stimulus without interference of the scanner noise (TR 8000 ms, 120 volumes). Functional data was processed using the Brain Voyager software. Single and group General Linear Models (GLM) were applied to the data. For the visual paradigm activation clusters were corrected for multiple comparisons after the Bonferroni method to an p-level of 0,05. The threshold for the auditory paradigm was chosen less strictly (auditory stimuli $p<0,000059$, without correction for multiple comparisons), due to the weaker signal of the data of the event related paradigm. For anatomical localization of activation clusters peak-voxel cluster were defined 
Table 1

SEMANTIC DECISION visual stimuli $\mathrm{p}$ (Bonf) $<0.05$

\begin{tabular}{|c|c|c|c|c|}
\hline & Control & $\mathrm{DF}$ & JPF & JAF \\
\hline cluster 1 & LEFT BA4 & LEFT BA8 & LEFT BA3 & RIGHT BA 22 \\
\hline cluster 2 & LEFT BA6 & LEFT BA6 & LEFT BA40 & RIGHT BA 46 \\
\hline cluster 3 & LEFT BA9 & LEFT BA6 & LEFT BA45 & RIGHT BA 6 \\
\hline cluster4 & LEFT BA22 & LEFT BA9 & LEFT BA21 & RIGHT BA10 \\
\hline cluster 5 & LEFT BA45 & LEFT BA39 & LEFT BA21 & RIGHT BA 6 \\
\hline cluster 6 & & LEFT BA21 & LEFT BA 40 & LEFT BA 9 \\
\hline cluster 7 & & LEFT BA3 & & LEFT CEREBELLUM \\
\hline cluster 8 & & LEFT BA21 & & LEFT BA 22 \\
\hline \multicolumn{5}{|c|}{ SEMANTIC DECISION auditory stimuli $p<0,000059$} \\
\hline & Control & $\mathrm{DF}$ & JPF & JAF \\
\hline cluster 1 & LEFT BA21 & LEFT BA13 & LEFT BA39 & RIGHT BA32 \\
\hline cluster 2 & LEFT BA22 & LEFT BA 22 & LEFT BA40 & RIGHT BA9 \\
\hline cluster 3 & LEFT BA 41 & & LEFT BA22 & RIGHT BA24 \\
\hline cluster 4 & & & LEFT BA43 & LEFT BA24 \\
\hline cluster 5 & & & & LEFT BA32 \\
\hline cluster 6 & & & & LEFT BA20 \\
\hline cluster 7 & & & & LEFT BA20 \\
\hline cluster 8 & & & & LEFT BA39 \\
\hline cluster 9 & & & & LEFT BA 22 \\
\hline cluster 10 & & & & LEFT BA42 \\
\hline cluster 11 & & & & LEFT BA21 \\
\hline
\end{tabular}

with a cluster threshold of 300 voxels for the visual condition and 150 voxels for the auditory condition. All participants performed a T1-weighted anatomical scan. All anatomical data were transformed into the common space of Talairach.

\section{Results}

In all 3 patients structural MRI showed the sequelae of a left frontal subcortical infarction in a similar localization but of different size. All three patients showed fully functional recovery of language; however JAF performed below one SD in the semantic (food and animals) and the phonological (letters M,P,R) verbal fluency task. JAF, but also JPF, admitted, as the only symptom, some word finding difficulties in the self evaluation form. In Table 1 the respective Brodmann areas of the peak-voxel VOIs are listed. The main pattern of recovery in patients DF and JPF was reorganization of language function in the dominant left hemisphere. The exception is patient JAF who had a partial language transfer. His neuronal network for language is much larger distributed (e.g. involvement of the left cerebellum). The homologue language areas (BA22 and BA46) of the right hemisphere are more activated by the visual stimuli of the language paradigm than their left counterparts, whereas heard language stimuli continue to be processed predominantly in the left hemisphere.

\section{Conclusion}

The results contrasts to what is known from perinatal brain lesions before language acquisition that are often associated with a complete language shift to the right hemisphere [4]. This suggests that an early commitment of the left hemisphere to language initiates an almost irreversible specialization [5-7]. Only when the left hemisphere is compromised by a sufficient large lesion language functions that are acquired later on tend to be transferred to the homologue areas of the contra-lateral hemisphere. In JAFs case the processing of written stimuli (acquired 4 years after lesion onset) was directed to the right hemisphere. Further research should investigate the underlying factors in the exceptional cases of transference of language function to the opposite brain hemisphere.

\section{References}

[1] D. Saur, R. Lange, A. Baumgaertner, V. Schraknepper, K. Willmes, M. Rijntjes and C. Weiller, Dynamics of language reorganization after stroke, Brain (2006), 1371-1384.

[2] J.M. Tillema, A.W. Byars, L.M. Jacola, M.B. Schapiro, V.J. Schmithorst, J.P. Szaflarski and S.C. Holland, Cortical reorganization of language functioning following perinatal left MCA stroke, Brain and Language (2008), 184-194.

[3] F. Liégeois, A. Connelly, J. Cross, S.G. Boyd, D.G. Gadian, F. Vargha-Khadem and T. Baldeweg, Language reorganization in children with early onset lesions of the left hemisphere: an fMRI study, Brain (2004), 1229-1236. 
[4] M. Staudt, K. Lidzba, W. Grodd, D. Wildgruber, M. Erb and I. Krägeloh-Mann, Right-Hemispheric Organization of Language Following Early Left-Sided Brain Lesions: Functional MRI Topography, NeuroImage (2002), 954-967.

[5] D.P. Anderson, A.S. Harvey, M.M. Saling, V. Anderson, M. Kean, D.F. Abbott, R.M. Wellard and G.D. Jackson, fMRI Lateralization of Expressive Language in Children with Cerebral Lesions, Epilepsia (2006), 998-1008.
[6] L.A. Balsamo, B. Xu, C.B. Grandin, J. Petrella, S.H. Braniecki, T.K. Elliott and W.D. Gaillard, A Functional Magnetic Resonance Imaging Study of Left Hemisphere Language Dominance in Children, Arch Neurol (2002), 1168-1174.

[7] I.P. Martins, C. Loureiro, S. Ramos and T. Moreno, Grammatical dissociation during acquired childhood aphasia. Developmental Medicine and Child Neurology (2009). 


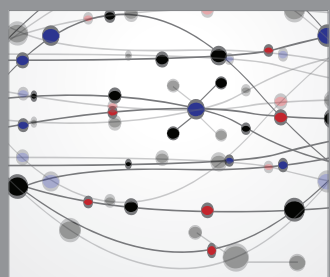

The Scientific World Journal
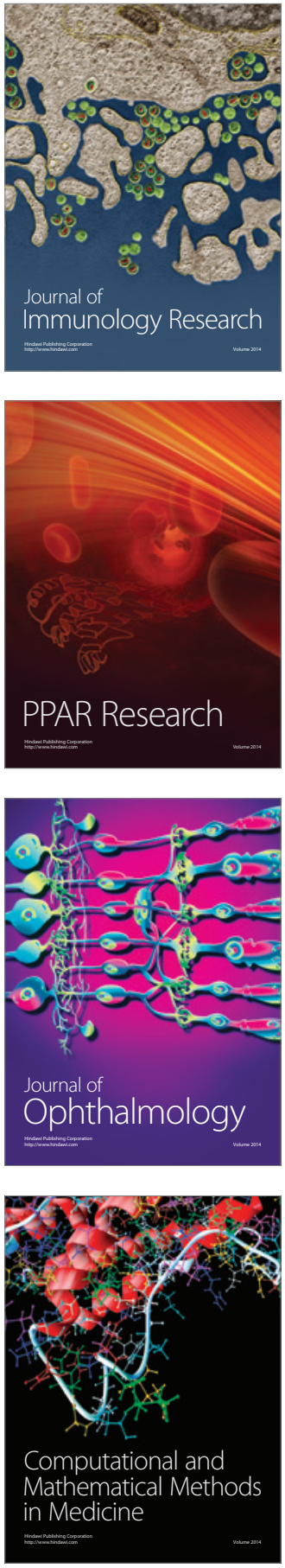

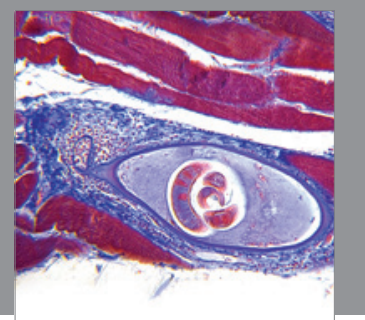

Gastroenterology

Research and Practice
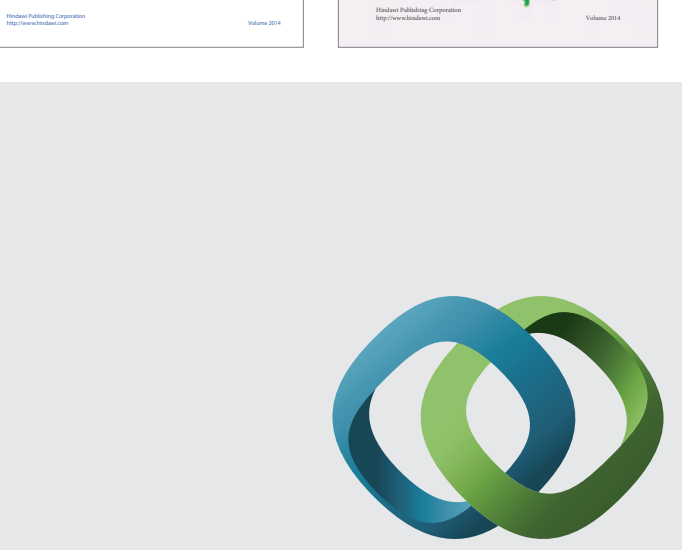

\section{Hindawi}

Submit your manuscripts at

http://www.hindawi.com
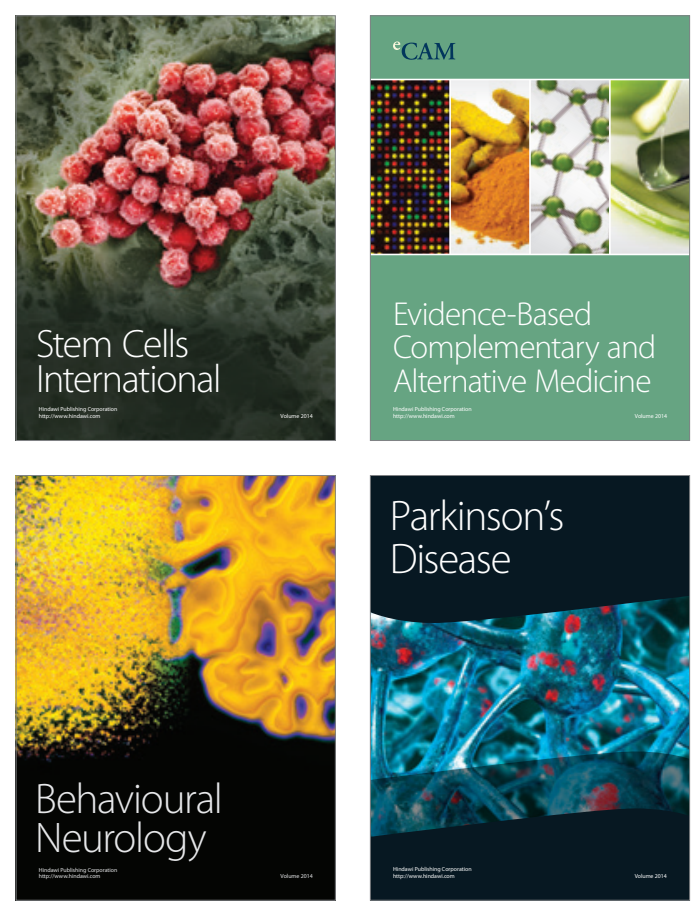

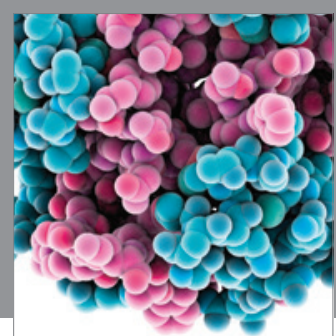

Journal of
Diabetes Research

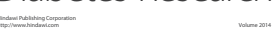

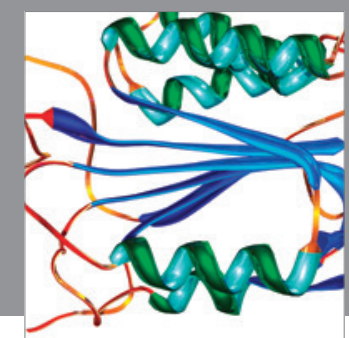

Disease Markers
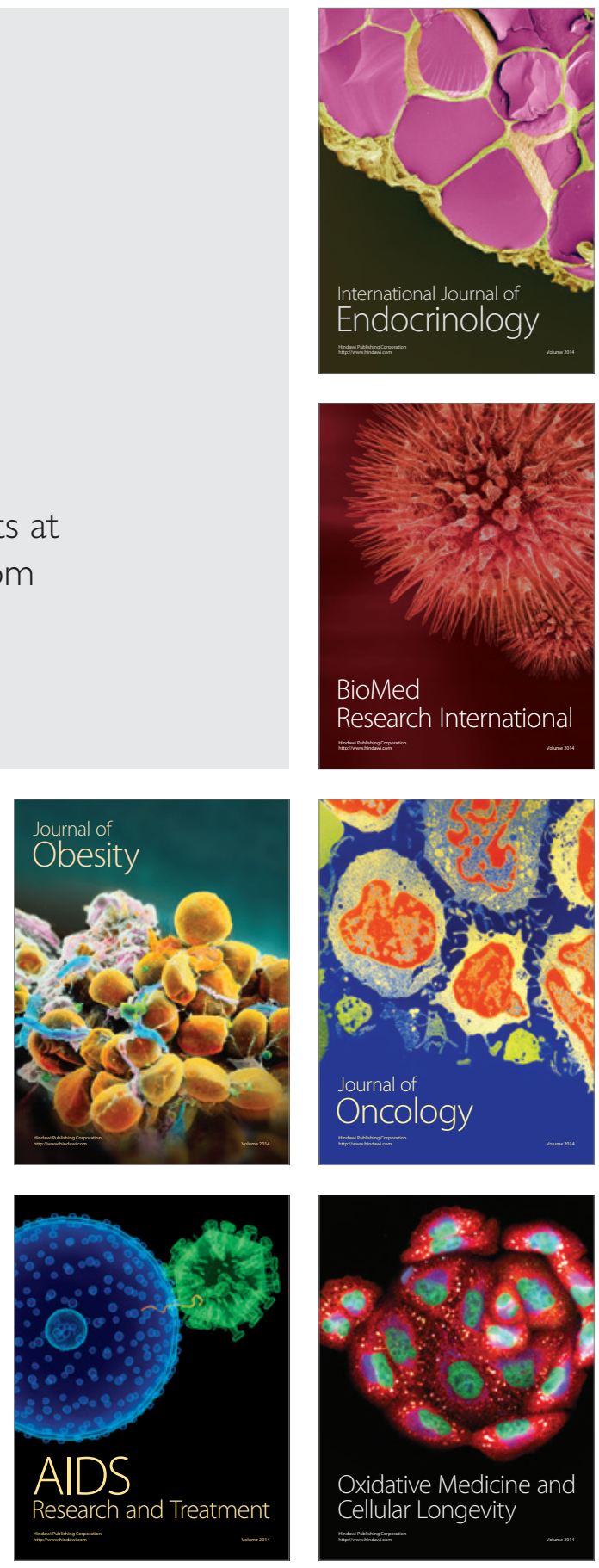